\title{
KLASIFIKASI SINYAL EMG PADA OTOT TUNGKAI SELAMA BERJALAN MENGGUNAKAN RANDOM FOREST
}

\author{
Darma Setiawan Putra ${ }^{1}$, Adhi Dharma Wibawa ${ }^{2}$, Mauridhi Hery Purnomo ${ }^{3}$ \\ ${ }^{1}$ Jurusan Teknik Informatika, Politeknik Aceh Selatan, Tapaktuan \\ ${ }^{2,3}$ Jurusan Teknik Multimedia dan Jaringan, Institut Teknologi Sepuluh Nopember, Surabaya \\ ${ }^{1}$ Jalan Merdeka Komplek Reklamasi Pantai, Tapaktuan, Aceh Selatan \\ ${ }^{2,3}$ Jalan Arif Rahman Hakim, Kampus ITS Sukolilo, Surabaya \\ email : darma_oke2000@yahoo.com, adhiosa@te.its.ac.id, hery@ee.its.ac.id
}

\begin{abstract}
Electromyography (EMG) signal is an electrical signal in the muscle layer during active motion. The way people walking is determined by the structure of the muscle and bones so that the way of walking is unique and must be able to used in biometric data. In this research, we classified the EMG data from eight lower limb muscle during normal walking: Rectus Femoris, Vastus Lateralis, Vastus Medialis, Bicep Femoris, Semitendinosus, Gastrocnemius Lateralis, Gastrocnemius Medialis, and Tibialis Anterior. Six healthy volunteer were involved for walking in GaitLab with 8 EMG electrodes attached on their muscle. They are performed one gait cycle and 3 walking trial. So the EMG dataset total for analized classification is 18 unit. Graph feature extraction and principal component analysis method was used to extract the feature of EMG data. Random Forest method was used to classify the EMG data based on subject. Training and testing method were used cross validation $(\mathrm{CV})$. The accuracy of classification using graph feature extraction method is $88.88 \%$ and using principal component analysis method is $72.22 \%$. In the result show that EMG data during walking of 8 lower limb muscles can be used to identity of gait biometric.
\end{abstract}

Keyword : EMG, Lower Limb Muscle, Gait Biometric, Principal Component Analysis, Gait Analysis.

\begin{abstract}
Abstrak
Sinyal electromyography (EMG) merupakan suatu sinyal elektrik yang terdapat dalam lapisan otot selama gerakan aktif. Cara orang berjalan ditentukan oleh struktur otot dan tulang sehingga cara berjalan ini adalah unik dan dapat digunakan sebagai data biometrik. Pada penelitian ini, kami mengklasifikasi data EMG dari delapan jenis otot tungkai selama percobaan berjalan normal: Rectus Femoris, Vastus Lateralis, Vastus Medialis, Bicep Femoris, Semitendinosus, Gastrocnemius Lateralis, Gastrocnemius Medialis, dan Tibialis Anterior. Enam orang subyek diminta untuk berjalan di laboratorium GaitLab dengan 8 buah elektroda EMG ditempel pada otot mereka. Subyek diminta untuk berjalan sebanyak 1 gait cycle dengan 3 kali pengambilan data. Total dataset EMG untuk klasifikasi adalah sebanyak 18 buah. Metode graph feature extraction dan principal component analysis digunakan untuk ekstraksi fitur data EMG. Metode Random Forest digunakan untuk mengklasifikasi data EMG berdasarkan subyek. Metode pelatihan dan pengujian data EMG menggunakan cross validation (CV). Akurasi klasifikasi yang dihasilkan dengan menggunakan metode graph feature extraction adalah sebesar $88.88 \%$ dan metode principal component analysis adalah sebesar $72.22 \%$. Hasil ini menunjukkan bahwa data EMG ketika berjalan dari 8 jenis otot tungkai dapat digunakan untuk identitas biometrik gaya berjalan (gait).
\end{abstract}

Kata kunci : EMG; Otot Tungkai; Biometrik Gait; Principal Component Analysis; Analisis Gait.

\section{Pendahuluan}

Setiap manusia memiliki gaya berjalan (gait) yang berbeda. Perbedaan ini disebabkan karena oleh struktur tulang dan komposisi otot tungkai yang melingkupinya. Perbedaan ukuran otot tungkai akan menghasilkan perbedaan sinyal EMG selama berjalan pada setiap orang. Pada saat otot berkontraksi maka otot akan mengeluarkan potensial listrik dengan besaran magnitudo tertentu dan pada saat otot berelaksasi maka potensial listrik akan berkurang secara berkala. Potensial listrik yang dihasilkan dari otot tungkai ini dapat direkam dan diukur dengan sebuah alat yang disebut electromyograph (EMG) [1]. Setiap orang memiliki sinyal EMG selama berjalan pada otot tungkai yang unik sehingga sinyal ini dapat digunakan untuk identitas biometrik. Sinyal EMG ini juga dapat diaplikasikan untuk program rehabilitasi pasien, pembuatan animasi cara berjalan seseorang ataupun pengembangan robot kaki yang dijalankan menggunakan pola sinyal EMG. 
Pengenalan manusia berdasarkan gerak berjalan (gait) telah dipublikasikan pada beberapa penelitian. Lee, et al [2] melakukan penelitian analisis gait berbasis video. Akuisisi citra gait manusia dengan menggunakan pakaian khusus yaitu tangan berwarna merah, kaki kanan dan badan berwarna hitam serta kaki kiri berwarna putih. Untuk segmentasi dilakukan dengan menggabungkan antara objek dan latar belakang kemudian melakukan filterisasi menggunakan Gaussian filter. Ekstraksi fitur menggunakan analisa histogram dan metode hough transform pada citra skeletonisasi untuk mendapatkan nilai dari kesepuluh fitur. Empat fitur merupakan kelompok jarak dan enam lainnya merupakan hasil pengukuran sudut. Wagg and Nixon [3] melakukan analisis gait dari jarak jauh secara real time menggunakan video dengan bentuk siluet seseorang. dari siluet tersebut akan diubah menjadi skeleton dan dari skeleton akan dicari fitur dari gerak jalan tersebut. Citra akan diproses menggunakan gaussian untuk menghilangkan derau kemudian diikuti dengan deteksi tepi Sobel. Nearest neighbor classifier digunakan untuk proses pengenalan dengan metode leave-one-out cross validation. Muazz and Nickel [4] melakukan penelitian menggunakan sensor accelerometer untuk pengenalan gait dengan kecepatan berjalan yang berbeda. Sensor accelerometer yang telah banyak terpasang di perangkat smartphone kemudian dipasang di tubuh objek. Ekstraksi cycle didasarkan pada akselerasi arah sumbu $\mathrm{x}$ yang dibandingkan dengan arah sumbu y dan z. Tujuh tahapan untuk melakukan ekstraksi cycle adalah interpolation, filtering, centring around zero, cycle length estimation, cycle detection, cycle normalization, deletion of unusual cycle, dan computation of typical cycle. Hasilnya menunjukkan bahwa kecepatan berjalan yang berbeda akan berpengaruh terhadap pengenalan gait.. Dianta [5] telah meneliti tentang pengenalan manusia berdasarkan data marker trayektori yang dipasang pada otot tungkai sebanyak 16 buah, 8 buah marker pada kaki kanan dan 8 buah marker pada kaki kiri. Pergerakan marker ini akan memiliki lintasan $x, y$ dan $z$ selama proses berjalan. Jumlah subyek yang dilibatkan sebanyak 8 orang. Seluruh data marker trayektori pada setiap subyek dilatih dan diuji menggunakan naïve bayesian untuk proses pengenalan. Hasilnya menunjukkan bahwa $98 \%$ dari data marker trayektori tersebut dapat mengenal siapa pemiliknya. Hal ini menunjukkan bahwa pola berjalan setiap orang memiliki keunikan sehingga dengan keunikan gaya berjalan tersebut dapat digunakan dalam bidang biometrik. Kaur et. al [6] telah meneliti tentang adanya perbedaan sinyal EMG pada otot tungkai selama berjalan dengan kecepatan normal dan cepat. Dalam penelitian tersebut mereka menganalisis sinyal EMG dengan menggunakan metode root mean square (RMS) dan median frequency (MDF). Adanya variasi nilai RMS dan MDF dari sinyal EMG pada setiap otot yang berbeda dapat digunakan sebagai pengetahuan tentang kecepatan berjalan manusia normal. Secara statistik variasi nilai RMS dan MDF ini dapat digunakan untuk mengetahui perubahan kecepatan berjalan tersebut.

Dalam penelitian ini, kami melakukan analisis gait berbasis sinyal EMG dengan melakukan pengklasifikasian sinyal EMG selama berjalan dengan kecepatan normal (self-selected speed) pada 8 otot tungkai Metode ektraksi fitur dalam penelitian ini menggunakan dua metode perbandingan yaitu graph feature extraction and principal component analysis. Hasil ekstraksi fitur akan dijadikan sebagai fitur untuk memprediksi kelas subyek dari data EMG. Klasifikasi ini dilakukan untuk mengetahui sejauhmana variasi pola sinyal EMG pada otot tungkai dimiliki oleh seseorang sehingga sinyal EMG ini dapat digunakan sebagai identitas biometrik gait.

\section{Metodologi Penelitian}

Adapun metodologi dari penelitian ini adalah seperti ditunjukkan pada Gambar 1.

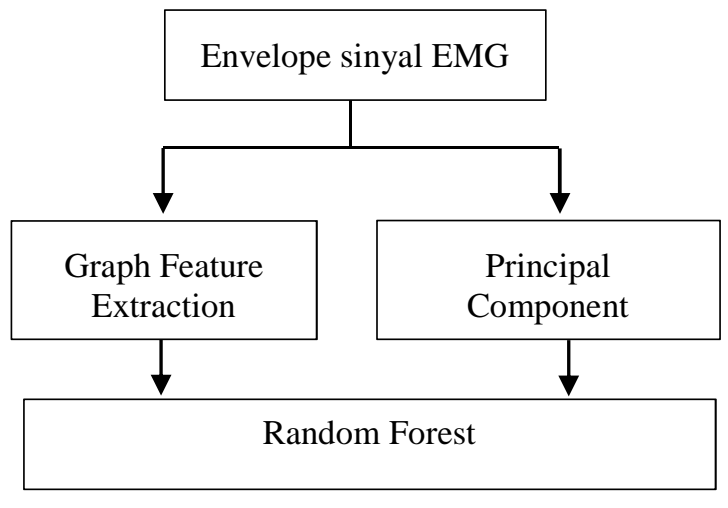

Gambar 1. Metodologi penelitian

Gambar 1 menjelaskan bahwa sinyal EMG yang telah berbentuk envelope sinyal akan diekstraksi untuk memperoleh fitur dengan menggunakan dua metode yaitu metode graph feature extraction dan principal component analysis. Hasil ekstraksi fitur dari masing-masing metode ini akan diklasifikasi dengan menggunakan naïve bayessian untuk mengetahui akurasi pengklasifikasian dari sinyal EMG pada otot tungkai selama berjalan berdasarkan subyek.

Dataset pada penelitian diadopsi dari penelitian Wibawa, et al [7] yang berjudul $A$ validation study on muscle activity prediction of a lower limb musculoskeletal model using EMG during normal walking. 


\subsection{Envelope Sinyal EMG}

Envelope sinyal EMG merupakan sinyal EMG yang telah melalui proses full wave rectification, filtering, dan smoothing dari raw sinyal EMG. Envelope dari raw sinyal EMG ini berguna untuk mengetahui waktu aktif otot dan mengukur level aktivasi. Bentuk envelope dari sinyal EMG pada otot Gastrocnemius Medialis (GM), Bicep Femoris $(B F)$, Gastrocnemius Lateralis (GL), dan Tibialis Anterior (TA) pada otot tungkai sebagaimana ditunjukkan oleh Gambar 2.

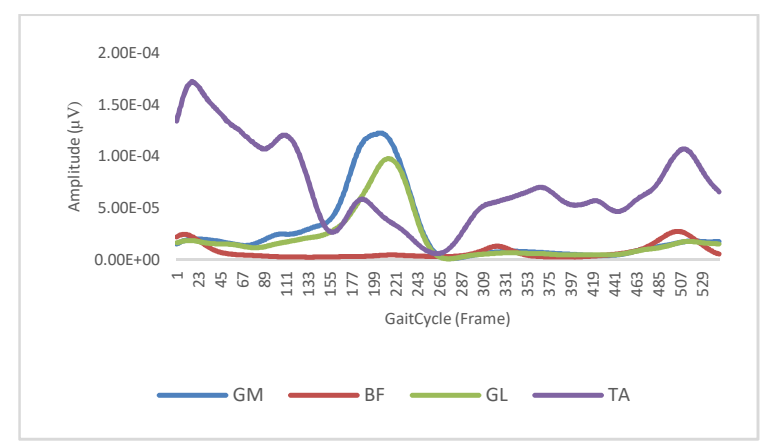

Gambar 2. Envelope sinyal EMG dari otot GM, BF, GL, dan TA 2.2 Graph Feature Extraction (GFE)

Graph feature extraction merupakan suatu teknik ekstraksi fitur dengan melakukan observasi pada ciri dari pola grafik sinyal EMG. Adapun langkah-langkah melakukan metode ekstraksi fitur graph feature extraction seperti ditunjukkan dalam alur pada Gambar 3.

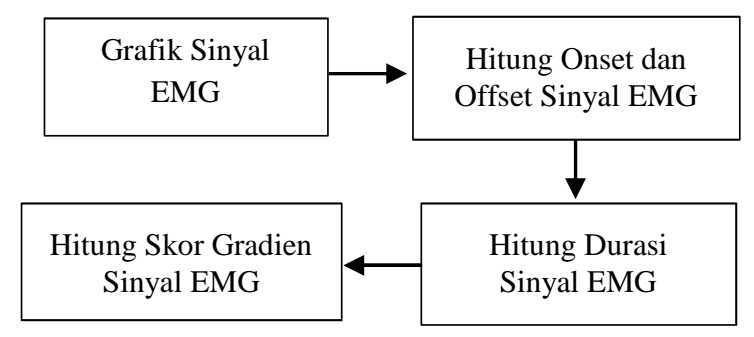

Gambar 3. Tahapan graph feature extraction

Onset merupakan titik awal kenaikan tegangan pada sinyal EMG sedangkan offset merupakan titik akhir penurunan tegangan pada sinyal EMG. Nilai threshold yang digunakan sebagai acuan untuk menentukan titik onset dan offset adalah $20 \%$ dari nilai amplitudo maksimum pada setiap otot [8]. Ilustrasi titik onset dan offset pada salahsatu envelope sinyal EMG dari otot gastrocnemius medialis sebagaimana ditunjukkan oleh Gambar 4 .

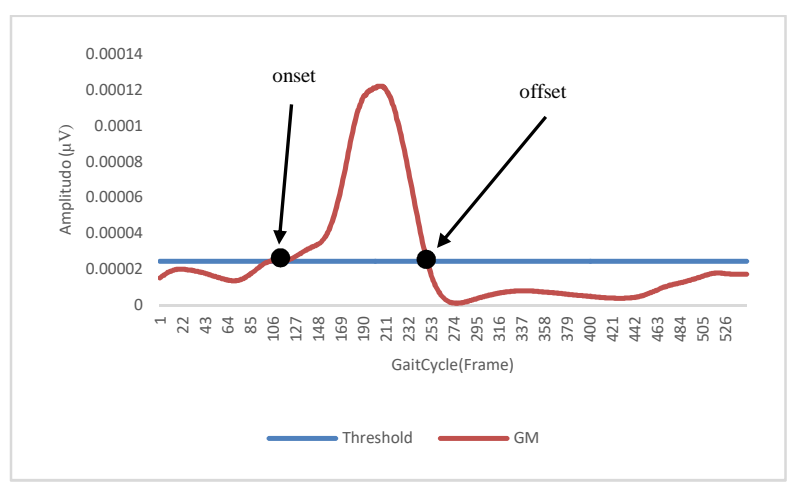

Gambar 4. Titik onset dan offset pada sinyal EMG

Durasi merupakan banyaknya waktu yang terjadi selama otot aktif dalam satu siklus berjalan (gait cycle). Perbedaan durasi ini sangat dipengaruhi oleh banyaknya otot yang aktif selama berjalan. Biasanya semakin lama aktifnya otot tungkai maka semakin panjang durasi waktu yang akan dihasilkan. Gambar 5 menunjukkan durasi waktu sinyal EMG dari otot gastrocnemius medialis.

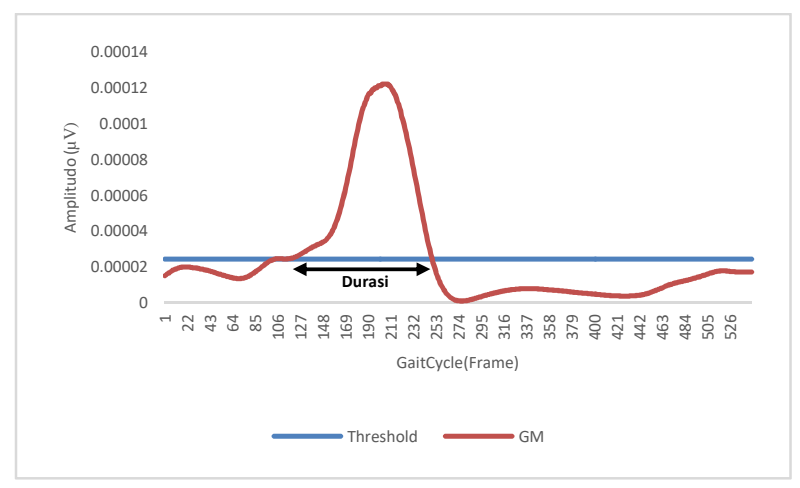

Gambar 5. Durasi sinyal EMG pada otot gastrocnemius medialis

Pada metode ini, fitur sinyal EMG diperoleh dengan menerapkan skor gradien. Skor gradien dihitung dengan melihat setiap perubahan gradien garis. Apabila gradien yang terjadi adalah gradien positif maka nilai perubahan tersebut diberi skor 2 . Apabila gradien yang terjadi adalah gradien negatif maka nilai perubahan tersebut diberi skor -1. Dan apabila tidak terjadi perubahan gradien maka perubahan tersebut diberi skor 0 . Nilai total dari skor gradien merupakan penjumlahan dari seluruh nilai gradien dari titik ke titik. Ilustrasi terkait dengan gradien positif, negatif dan nol adalah seperti Gambar 6. 


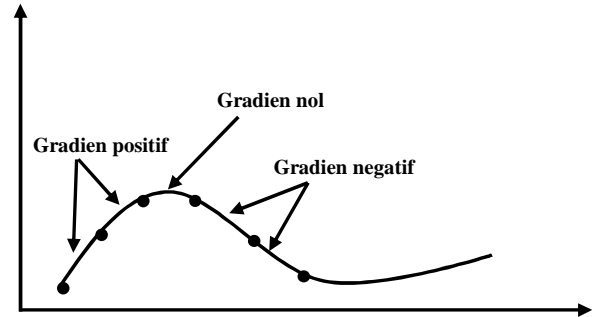

Gambar 6. Skor gradien sinyal EMG

Berdasarkan Gambar 4 maka skor gradien dihitung hanya pada sinyal di atas nilai threshold pada setiap titik onset dan titik offset.

\subsection{Principal Component Analysis (PCA)}

PCA merupakan suatu teknik yang biasa digunakan untuk mengetahui pola dalam sekumpulan data. Metode PCA ini berusaha mencari proyeksi terbaik yang dapat merepresentasikan suatu kumpulan data. Metode ini biasa digunakan dalam teknik kompresi untuk memperoleh dimensi data yang lebih kecil tanpa kehilangan informasi yang terkandung di dalamnya [9]. Adapun langkah-langkah untuk melakukan ekstraksi fitur sinyal EMG menggunakan metode PCA seperti ditunjukkan oleh Gambar 7.

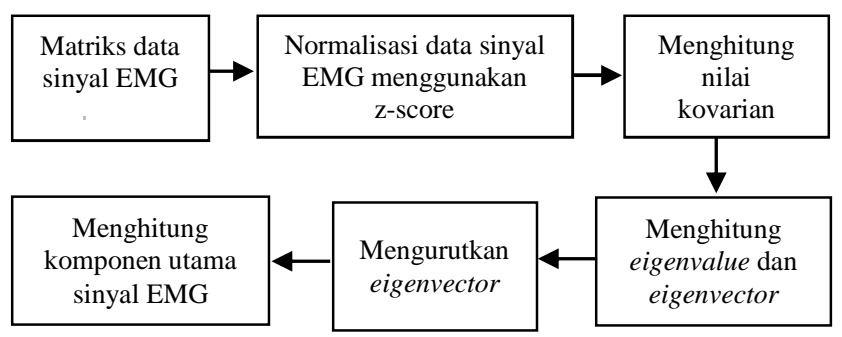

Gambar 7. Tahapan principal component analysis

Normalisasi data diperlukan untuk mendapatkan dalam dalam skala yang sama [10]. Setiap data $(x)$ dalam satu dimensi dikurangi dengan mean $(\mu)$ dimensi tersebut dan dibagi dengan nilai standar deviasi $(\sigma)$ dari dimensi itu juga. Normalisasi menggunakan metode $z$-score seperti ditunjukkan oleh Persamaan 1.

$$
z-\text { score }=\frac{x-\mu}{\sigma}
$$

Kovarian merupakan hubungan keterkaitan antara dua variabel independen. Jika diketahui variabel $x$ dan $y$ dengan jumlah sampel data $n$ maka nilai kovarian dari $x$ dan $y$ dapat diketahui dengan menggunakan Persamaan 2.

$$
\operatorname{cov}(x, y)=\frac{\sum_{i=1}^{n}\left(x_{i}-\bar{x}\right)\left(y_{i}-\bar{y}\right)}{n-1}
$$

Vektor eigen merupakan vektor kolom bukan nol yang jika dikalikan dengan suatu matriks yang berukuran $n \times n$ akan menghasilkan vektor lain yang memiliki kelipatan dari vektor eigen itu sendiri. Jika ada sebuah matriks $A$ dan $v$ maka perkalian matriks untuk memperoleh vektor eigen dan nilai eigen seperti ditunjukkan oleh Persamaan 3.

$$
A v=\lambda v
$$

Persamaan 3 diatas berlaku untuk $v \neq 0$ dan $v$ disebut dengan vektor eigen (eigen vector) dari suatu matriks $A$. Vektor eigen akan selalu beriringan dengan nilai eigen (eigen value). Notasi $\lambda$ disebut dengan nilai eigen. Merujuk ke Persamaan 3 maka vektor eigen akan diperoleh dengan menggunakan Persamaan 4 dan nilai eigen akan diperoleh dengan menggunakan Persamaan 5.

$$
\begin{array}{r}
(A-\lambda I) \nu=0 \\
\operatorname{det}(\lambda I-A)=0
\end{array}
$$

Untuk memperoleh vektor eigen dan nilai eigen pada Persamaan 4 dan 5 menggunakan bantuan matriks identitas $(I)$.

Principal component dari sinyal EMG diperoleh dengan mengalikan variabel data $x$ dengan matriks vektor eigen $v$ seperti ditunjukan oleh Persamaan 6.

$$
p c=x v
$$

\subsection{Random Forest}

Random forest adalah algoritma klasifikasi dan regresi yang menjadi bagian dari kelompok ensemble learning [11]. Metode random forest merupakan pengembangan dari decision tree dimana setiap decision tree telah dilakukan proses pelatihan dengan menggunakan sampel individu. Random forest yang dihasilkan memiliki banyak tree dan setiap tree ditanam dengan cara yang sama. Seiring dengan bertambahnya dataset, maka tree juga ikut berkembang.

Dalam random forest, pemilihan atribut pada setiap kali sebuah node akan dipecah akan diambil secara acak. Setiap tree diberi sampel data pelatihan dengan menggunakan metode bagging dan tiap tree dibangun menggunakan metode yang sama untuk membangun CART (classification and regression tree). Metode ini menerapkan metode bootstrap aggregating (bagging) dan random feature selection [11]. 
Proses prediksi random forest seperti ditunjukkan oleh Gambar 8.

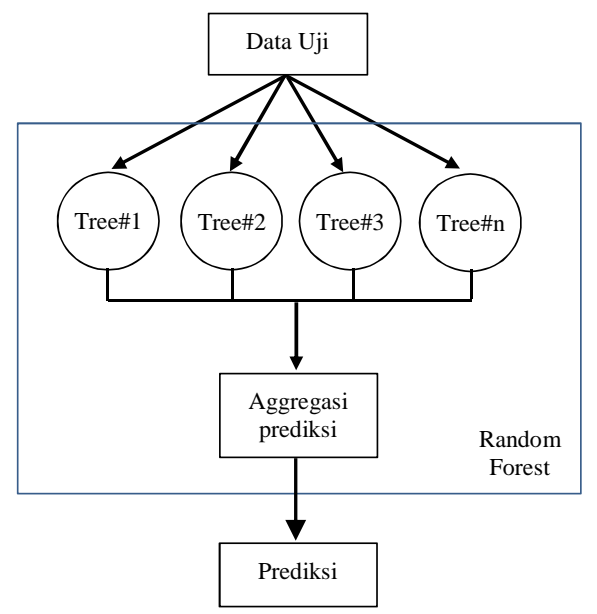

Gambar 8. Proses prediksi random forest

Random forest yang dihasilkan memiliki banyak tree dan setiap tree akan tumbuh dengan cara yang sama. Tree dengan variabel $x$ akan ditempatkan pada jarak yang jauh dengan tree dengan variabel y. Sejalan dengan bertambahnya dataset maka tree pun ikut berkembang. Penempatan tree yang saling berjauhan akan memudahkan dalam deteksi jenis tree. Tree yang berada di sekitar tree $x$ maka tree tersebut merupakan perkembangan dari tree $x$ sedangkan tree yang berada disekitar tree $y$ maka tree tersebut merupakan perkembangan dari tree $y$. Pembangunan tree akan berhenti ketika data sudah homogen atau jika batas jumlah data minimum sudah terlewati.

Penelitian ini menggunakan weka software versi 3.8 [12] untuk melakukan klasifikasi subyek data EMG. Parameter random forest pada weka yang digunakan antara lain : besar kedalaman tree adalah 7 dan jumlah iterasi adalah 80 . Jenis validasi yang digunakan adalah $k$-cross validation dengan nilai $\mathrm{k}=3$.

Untuk mengetahui kinerja dari classifier [13], penelitian ini akan melakukan evaluasi dengan menggunakan Persamaan 7, 8, dan 9.

$$
\begin{array}{r}
\text { akurasi }=\frac{T P+T N}{T P+T N+F P+F N} \\
\text { sensitifitas }=\frac{T P}{T P+F N} \\
\text { presisi }=\frac{T P}{T P+F P}
\end{array}
$$

\section{Hasil dan Pembahasan}

Penelitian ini menggunakan metode random forest classifier untuk pengklasifikasian data EMG pada otot tungkai selama berjalan. Adapun hasil pengklasifikasian sinyal EMG berdasarkan subyek yang menggunakan metode graph feature extraction (GFE) dan metode principal component analysis (PCA) sebagaimana ditunjukkan oleh

\begin{tabular}{|c|c|c|c|c|c|c|c|}
\hline & \multicolumn{6}{|c|}{ Predicted } \\
\hline & & S\#1 & S\#2 & S\#3 & S\#4 & S\#5 & S\#6 \\
\hline \multirow{6}{*}{ 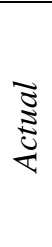 } & S\#1 & 3 & 0 & 0 & 0 & 0 & 0 \\
\hline & S\#2 & 1 & 2 & 0 & 0 & 0 & 0 \\
\hline & S\#3 & 1 & 0 & 2 & 0 & 0 & 0 \\
\hline & S\#4 & 0 & 0 & 0 & 3 & 0 & 0 \\
\hline & S\#5 & 0 & 0 & 0 & 0 & 3 & 0 \\
\hline & S\#6 & 0 & 0 & 0 & 0 & 0 & 3 \\
\hline
\end{tabular}
confusion matrix pada Tabel 1 dan Tabel 2.

Tabel 1. Hasil pengklasifikasian metode GFE

\begin{tabular}{|c|c|c|c|c|c|c|c|}
\hline & \multicolumn{6}{|c|}{ Predicted } \\
\hline & & S\#1 & $\mathrm{S} \# 2$ & S\#3 & $\mathrm{S} \# 4$ & S\#5 & S\#6 \\
\hline \multirow{6}{*}{ 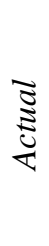 } & S\#1 & 0 & 0 & 2 & 1 & 0 & 0 \\
\hline & $\mathrm{S} \# 2$ & 0 & 1 & 0 & 1 & 0 & 1 \\
\hline & S\#3 & 0 & 0 & 3 & 0 & 0 & 0 \\
\hline & S\#4 & 0 & 0 & 0 & 3 & 0 & 0 \\
\hline & $\mathrm{S} \# 5$ & 0 & 0 & 0 & 0 & 3 & 0 \\
\hline & S\#6 & 0 & 0 & 0 & 0 & 0 & 3 \\
\hline
\end{tabular}

Tabel 2. Hasil pengklasifikasian metode PCA

*S=Subyek

Pada Tabel 1 menunjukkan bahwa data EMG milik subyek1, subyek4, subyek5, dan subyek6 berhasil diklasifikasi dengan benar (True Positif=TP) untuk semua sampel data EMG. Sementara itu, data EMG untuk subyek2 dan subyek3 terjadi misklasifikasi sebanyak masingmasing 1 sampel data EMG (False Negative $=F N)$.

Pada Tabel 2 memperlihatkan bahwa data EMG milik subyek3, subyek4, subyek5, dan subyek6 berhasil diklasifikasi dengan benar (True Positif $=T P$ ) untuk semua sampel data EMG. Sedangkan untuk subyek1 terjadi misklasifikasi (False Negative $=F N$ ) untuk semua sampel data EMG sedangkan subyek2 terjadi misklasifikasi sebanyak 2 sampel data EMG.

Dengan mengacu pada Persamaan 8 dan 9 maka diperoleh nilai sensitifitas dan presisi untuk masingmasing metode ekstraksi seperti ditunjukkan oleh Tabel 3.

Tabel 3. Evaluasi kinerja classifier

\begin{tabular}{|c|c|c|c|c|c|c|c|}
\hline $\begin{array}{c}\text { Metod } \\
\text { e }\end{array}$ & Evaluator & $\begin{array}{c}\text { S\# } \\
1\end{array}$ & S\#2 & S\#3 & $\begin{array}{c}\text { S\# } \\
4\end{array}$ & $\begin{array}{c}\text { S\# } \\
5\end{array}$ & S\#6 \\
\hline \multirow{3}{*}{ GFE } & $\begin{array}{c}\text { Sensitifita } \\
\text { s }\end{array}$ & 1 & $\begin{array}{c}0.6 \\
7\end{array}$ & $\begin{array}{c}0.6 \\
7\end{array}$ & 1 & 1 & 1 \\
\cline { 2 - 8 } & Presisi & 0.6 & 1 & 1 & 1 & 1 & 1 \\
\hline
\end{tabular}




\begin{tabular}{|c|c|c|c|c|c|c|c|}
\hline \multirow{3}{*}{ PCA } & $\begin{array}{c}\text { Sensitifita } \\
\text { s }\end{array}$ & 0 & $\begin{array}{c}0.3 \\
3\end{array}$ & $\begin{array}{c}0.6 \\
7\end{array}$ & 1 & 1 & 1 \\
\cline { 2 - 8 } & Presisi & 0 & 1 & $\begin{array}{c}0.6 \\
7\end{array}$ & 0.5 & 1 & $\begin{array}{c}0.7 \\
5\end{array}$ \\
\hline
\end{tabular}

Tabel 3 memperlihatkan bahwa sensifitas dan presisi untuk metode GFE dan PCA pada pengklasifikasian data EMG yang paling rendah adalah pada subyek1 sedangkan sensitifitas dan presisi pengklasifikasian untuk metode GFE dan PCA pada pengklasifikasian data EMG yang paling tinggi adalah pada subyek5. Hal ini dapat menunjukkan juga bahwa subyek5 memiliki sinyal EMG pada otot tungkai ketika berjalan yang paling unik bila dibandingkan dengan subyek yang lain sedangkan subyek1 memiliki sinyal EMG pada otot tungkai yang kurang unik.

Apabila menggunakan Persamaan 6 maka diperoleh akurasi pengklasifikasian untuk masingmasing metode adalah $88.88 \%$ untuk metode graph feature extraction dengan misklasifikasi sebanyak 2 sampel data EMG dan $72.22 \%$ untuk metode principal component analysis dengan misklasifikasi sebanyak 4 sampel data EMG.

\section{Kesimpulan}

Dari hasil dan pembahasan yang telah disampaikan pada bagian 3 dapat disimpulkan bahwa sinyal EMG pada otot tungkai merupakan sinyal yang berbeda antara satu subyek dengan subyek yang lain. Tingkat perbedaan ini dikarenakan oleh variasi gaya berjalan (gait) yang dimiliki oleh seseorang. Ciri dari sinyal EMG pada setiap subyek selama berjalan dapat digunakan untuk mengidentifikasi subyek tersebut. Dengan menggunakan metode ekstraksi fitur graph feature extraction diperoleh akurasi pengklasifikasian sebesar $88.88 \%$ dan metode principal component analysis diperoleh akurasi pengklasifikasian sebesar $72.22 \%$.

Dengan akurasi klasifikasi pada kedua metode tersebut dapat dikatakan bahwa pola sinyal EMG pada otot tungkai selama berjalan untuk keenam subyek masih dapat dikategorikan sebagai sinyal EMG yang unik sehingga dengan pola sinyal EMG yang unik tersebut dapat digunakan sebagai identitas biometrik gait. Untuk penelitian kedepan, jumlah partisipan yang dilibatkan dapat ditambah sehingga hasil dan akurasi yang diperoleh dapat menjadi lebih baik. Classifier jenis yang lain dapat juga diujicoba untuk memperoleh perbandingan akurasi klasifikasi.

\section{Daftar Pustaka}

[1] P. Konrad, "The ABC of EMG A Practical Introduction to Kinesiological Electromyography," Noraxon Inc, no. April, pp. 1-60, 2005.

[2] H. Lee, L. Guan, and I. Lee, "Video Analysis of
Human Gait and Posture to Determine Neurological Disorders," Eurasip J. Image Video Process., vol. 2008, 2008

[3] D. K. Wagg and M. S. Nixon, "On Automated Model-Based Extraction and Analysis of Gait," Proc. - Sixth IEEE Int. Conf. Autom. Face Gesture Recognit., pp. 11-16, 2004.

[4] M. Muaaz and C. Nickel, "Influence of Different Walking Speeds and Surfaces on AccelerometerBased Biometric Gait Recognition,” 2012 35th Int. Conf. Telecommun. Signal Process. TSP 2012 Proc., pp. 508-512, 2012.

[5] A. F. Dianta, "Pengenalan Seseorang Berbasis Skoring Data Trayektori Gaya Berjalan (Gait) Menggunakan Naive Bayessian,", Tesis, ITS, Surabaya, 2015.

[6] M. Kaur and S. Mathur, "EMG analysis for identifying walking patterns in healthy males," pp. 65-68, 2015.

[7] A. D. Wibawa, N. Verdonschot, J. G. M. Burgerhof, I. K. E. Purnama, M. S. Andersen, and J. P. K. Halbertsma, "A Validation Study on Muscle Activity Prediction of a Lower Limb Musculoskeletal Model using EMG During Normal Walking," pp. 260-264, 2013.

[8] G. Kamen and D. A. Gabriel, Essential of Electromyography. Human Kinetic, 2010.

[9] G. Bosco, "Principal component analysis of electromyographic signals: An overview," Open Rehabil. J., vol. 2, pp. 127-131, 2010.

[10] S. G. K. Patro and K. Kumar, "Normalization: A Preprocessing Stage," 2015.

[11] L. E. O. Breiman, "Random Forests," pp. 5-32, 2001.

[12] http://www.cs.waikato.ac.nz/ml/weka/

[13] D. M. W. Powers, "Evaluation: From Precision, Recall and F-Factor to ROC , Informedness, Markedness \& Correlation," no. December, 2007. 